\title{
Communication \\ Upgrading of Wash Oil through Reduction of Nitrogen-Containing Compounds
}

\author{
Su Jin Kim
}

check for

updates

Citation: Kim, S.J. Upgrading of Wash Oil through Reduction of Nitrogen-Containing Compounds. Processes 2021, 9, 1869. https:// doi.org/10.3390/pr9111869

Academic Editor: Jean Claude Assaf

Received: 22 September 2021

Accepted: 18 October 2021

Published: 20 October 2021

Publisher's Note: MDPI stays neutral with regard to jurisdictional claims in published maps and institutional affiliations.

Copyright: (C) 2021 by the author. Licensee MDPI, Basel, Switzerland. This article is an open access article distributed under the terms and conditions of the Creative Commons Attribution (CC BY) license (https:/ / creativecommons.org/licenses/by/ $4.0 /)$.
Department of Chemical Engineering, Chungwoon University, Incheon 22100, Korea; sujkim@chungwoon.ac.kr

\begin{abstract}
As part of improving the quality of wash oil, the reduction of three kinds of nitrogencontaining compounds (NCs), including quinoline (QU), iso-quinoline (IQU), and indole (IN), found in wash oil was examined by liquid-liquid equilibrium extraction. The wash oil and an aqueous solution of formamide were used as the raw material and the solvent, respectively. Increasing the volume fraction of water in the solvent in the initial state $\left(\mathrm{y}_{\mathrm{w}, 0}\right)$ resulted in a decrease in the distribution coefficients of each NC, while inversely, the selectivity of each NC in reference to 2-methylnaphthalene increased. The selectivity ranges of QU, IQU and IN at $\mathrm{y}_{\mathrm{w}, 0}=0.05 \sim 0.3$ were 19 57, 19 56 and 50 79, respectively. Through five stages of equilibrium extraction performed under the condition of $\mathrm{y}_{\mathrm{w}, 0}=0.05$, the concentrations of QU and IQU contained in the raffinate oil recovered at the fifth stage were reduced by about $69 \%$ and $65 \%$ compared to those contained in the wash oil. The concentration of IN in particular, a useful compound in the chemical industry, which is a raw material for pharmaceuticals, dyes, and fragrances, was reduced by $93.4 \%$ through a five-stage extraction operation. The formamide extraction method of this study was highly efficient in reducing the NC present in the wash oil, showing the feasibility of this method.
\end{abstract}

Keywords: coal tar; wash oil; nitrogen-containing compounds; indole; formamide equilibrium extraction

\section{Introduction}

Wash oil produced from a distillation fraction (distilled temperature $500-550 \mathrm{~K}$ ) of coal tar contains a number of valuable nitrogen-containing compounds (NCs), such as a quinoline (QU), iso-quinoline (IQU), quinaldine and indole (IN), which are used in the production of pharmaceuticals, perfumes, pigments, dyes and pesticides [1-3]. Conversely, the NCs mentioned above are undesirable impurities in wash oil due to their contribution to air pollution and unpleasant odors. At present, QU and mixtures containing more than $0.1 \%$ QU are classified as hazardous chemicals (carcinogens, skin irritants, etc.). Therefore, wash oil containing about $1.4 \% \mathrm{QU}$ is a hazardous chemical, so there are many restrictions on its transportation, handling, etc. For the above reasons, the improvement of wash oil quality according to the reduction of NCs and the review of the purification of useful components, such as IN, using a crude NC mixture recovered through the quality improvement process are considered to be very meaningful from the viewpoint of recycling resources.

To date, since the crude separation of NC from the coal tar fraction is a reaction extraction using an acid and a base, the operation is complicated, and has the disadvantage that it is impossible to recover and reuse the solvent [4]; thus, the development of a simpler and more efficient separation method is required. Extraction using ionic liquids [5-7], supercritical extraction [8,9], azeotropic distillation and traditional extraction methods [1-4,10-13] using various organic solvents, such as methanol, ethanol and formamide, have been studied for the reduction of NCs contained in the coal tar fraction. Among them [4,11,13], it has been reported that NCs present in the coal tar fraction can be reduced in a convenient and efficient manner by using an aqueous solution of methanol as a conventional extraction method. However, this methanol extraction method is not satisfactory from a separation point of view because of the low selectivity of NCs. 
In a previous study [3], we examined the effects of experimental factors on the reduction of NCs using eight kinds of traditional extraction solvents and a model coal tar fraction consisting of nine kinds of components. In this review, it was reported that the aqueous solution of formamide is the optimal solvent in terms of the balance between the distribution coefficient and the selectivity of NCs.

This study was conducted to improve the quality of wash oil by reducing the NCs contained within it. In this review, we investigated the effect of the volume fraction of water in the solvent in the initial state $\left(\mathrm{y}_{\mathrm{w}, 0}\right)$ on the reduction of NCs present in wash oil using the aqueous solution formamide. In addition, to confirm the efficacy of reducing NCs through the batch multistage extraction under fixed extraction conditions, we performed a five-stage equilibration extraction.

\section{Materials and Experimental Methods}

\subsection{Materials}

As a raw material of this study, wash oil was supplied by OCI Company Ltd. (Seoul, Korea). Naphthalene (NA, 99\% purity), QU (98\% purity), IQU (97\% purity), IN ( $\geq 99 \%$ purity), quinaldine ( $\geq 95 \%$ purity), 2-methylnaphthalene (2MNA, 97\% purity), 1-methylnaphthalene ( $\geq 95 \%$ purity), biphenyl (BP, $\geq 99.5 \%$ purity), dibenzofuran (DBF, $98 \%$ purity) and fluorene ( $98 \%$ purity), which were used for the GC identification or quantification of the constitutive components of the wash oil, were purchased from SigmaAldrich, Seoul, Korea. Formamide ( $\geq 99.5 \%$ purity), used as a solvent in this study, was also purchased from Sigma-Aldrich, Seoul, Korea. In this study, the above-mentioned 11 kinds of commercial reagents were used without further purification.

\subsection{Experimental Method}

A schematic diagram for the extraction method used in this study is presented in Figure 1 [2]. To make a solvent of a certain concentration, the formamide was mixed with tap water. Erlenmeyer flasks of $1 \mathrm{~L}$ containing a certain amount of the feed $\left(\mathrm{R}_{0}\right.$ : the wash oil, $R_{1}-R_{4}$ : the raffinate phase recovered from each stage) and the fresh solvent $\left(S_{1}-S_{5}\right)$ were placed in a shaking water bath maintained at the experimental temperature and vibrated for a certain time to reach a liquid-liquid equilibrium. After reaching the equilibrium, the mixture was settled for an aliquot of time, and the raffinate phase and the extract phase were separated using a $1 \mathrm{~L}$ separatory funnel, and then the mass of each phase was measured. The separated raffinate phase and a fresh aqueous solution of formamide were used as a raw material and a solvent at the next stage, respectively. Irrespective of the number of stages, $400 \mathrm{~mL}$ of the fresh solvent was charged in a $1 \mathrm{~L}$ Erlenmeyer flask. The raffinate phases and the extract phases recovered from the equilibrium extraction of each stage were analyzed by adding a small amount of acetone, and their compositions were determined. The analysis of two phases was carried out by a gas chromatograph (GC, Hewlett Packard Co., Houston, TX, USA, HP 6890: capillary column, HP-1 (60 mL, $0.32 \mathrm{~mm}$ I.D.)) equipped with flame ionization detector (FID). The analysis conditions of the samples were as follows: carrier gas, $\mathrm{N}_{2}$; volume flow rate, $1 \mathrm{~mL} / \mathrm{min}$; injection temperature, $523 \mathrm{~K}$; sample volume, $1 \mu \mathrm{L}$; splitting ratio, 0.025 ; column temperature, maintained at $383 \mathrm{~K}$ for $3 \mathrm{~min}$, then increased at a rate of $5 \mathrm{~K} / \mathrm{min}$ to $523 \mathrm{~K}$, then $14 \mathrm{~K} / \mathrm{min}$ to $593 \mathrm{~K}$; detector temperature, $593 \mathrm{~K}$.

\subsection{Material Systems and Experimental Conditions}

The material systems used for this study and the experimental conditions are summarized in Table 1 . The wash oil $\left(400 \mathrm{~mL} \mathrm{R}_{0}\right)$, and the raffinate phases $\left(\mathrm{R}_{1}-\mathrm{R}_{4}\right)$, which were recovered from each stage after reaching liquid-liquid equilibrium, were used as the raw materials. The fresh aqueous solution of formamide $\left(400 \mathrm{~mL} \mathrm{~S}_{1}-\mathrm{S}_{5}\right)$ was used as a solvent. The volume fraction of the solvent to a raw material in the initial state $\left(S_{1} / R_{0}\right)$, the operating temperature $(\mathrm{T})$ and the volume of the fresh solvent added to each stage were 
fixed and constant. The number of equilibrium extractions ( $n$ ), the volume fraction of water in the solvent in the initial state $\left(\mathrm{y}_{\mathrm{w}, 0}\right)$ and the liquid-liquid contact time $(\mathrm{t})$ were changed.

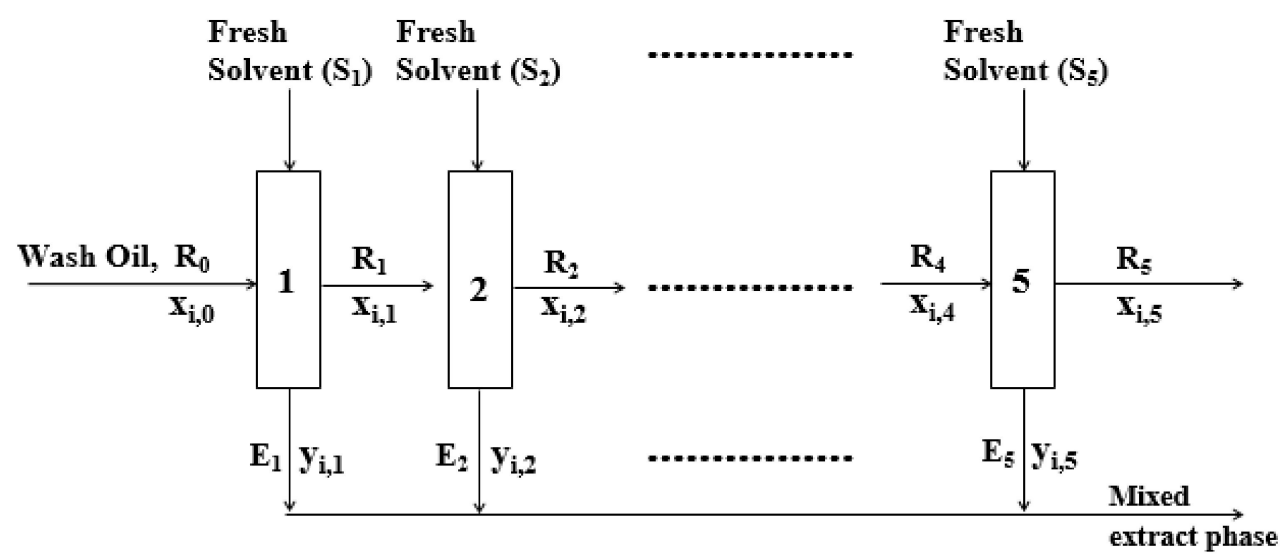

Figure 1. Schematic diagram for extraction method [2]. R: raffinate phase, E: extract phase, i: component i, $1,2,3,4,5$ : number of equilibrium extraction.

Table 1. Material systems and experimental conditions.

\begin{tabular}{lc}
\hline System & \\
\hline Feed: wash oil and raffinate phases & \\
Solvent: aqueous solution of formamide & \\
\hline Experimental Conditions & $12 \sim 96$ \\
\hline Liquid-liquid contact time, $\mathrm{t}(\mathrm{h})$ & $1 \sim 5$ \\
Number of equilibrium extractions, $n(-)$ & 303 \\
Operating temperature, $\mathrm{T}(\mathrm{K})$ & 400 \\
Volume of fresh solvent $(\mathrm{mL})$ & $0.05 \sim 0.3$ \\
Volume fraction of water in solvent in initial state, $\mathrm{y}_{\mathrm{w}, 0}(-)$ & 1 \\
\hline Volume ratio of solvent to feed in initial state, $\mathrm{S}_{1} / \mathrm{R}_{0}(-)$ & \\
\hline
\end{tabular}

\section{Results and Discussion}

\subsection{Gas Chromatogram of Wash Oil}

Figure 2a presents the gas chromatogram of the wash oil and the component names of the identified compounds. They were identified through analysis by adding a small amount of 10 standard reagents purchased from Sigma-Aldrich, Korea, as mentioned above. From the GC identification, we can see that the wash oil contains a relatively small amount of NC, but a large amount of bicyclic aromatic compounds (2MNA, 1-methylnaphthalene) and BP. The compositions of the six compounds quantified in this study are shown in Table 2. The compositions of QU, IQU and IN, which are the components of which this study aims to reduce the concentrations, were about $1.4 \%, 1.7 \%$ and $4.4 \%$, respectively.

Table 2. Composition of feed (wash oil).

\begin{tabular}{lc}
\hline \multicolumn{1}{c}{ Component } & Mass Fraction (-) \\
\hline Naphthalene $\left(\mathrm{NA}, \mathrm{C}_{10} \mathrm{H}_{8}\right)$ & 0.033 \\
Quinoline $\left(\mathrm{QU}, \mathrm{C}_{9} \mathrm{H}_{7} \mathrm{~N}\right)$ & 0.014 \\
Iso-quinoline $\left(\mathrm{IQU}, \mathrm{C}_{9} \mathrm{H}_{7} \mathrm{~N}\right)$ & 0.017 \\
Indole $\left(\mathrm{IN}, \mathrm{C}_{8} \mathrm{H}_{7} \mathrm{~N}\right)$ & 0.044 \\
2-Methylnaphthalene $\left(2 \mathrm{MNA}, \mathrm{C}_{11} \mathrm{H}_{10}\right)$ & 0.335 \\
Biphenyl $\left(\mathrm{BP}, \mathrm{C}_{12} \mathrm{H}_{10}\right)$ & 0.087 \\
Others & 0.470 \\
\hline
\end{tabular}




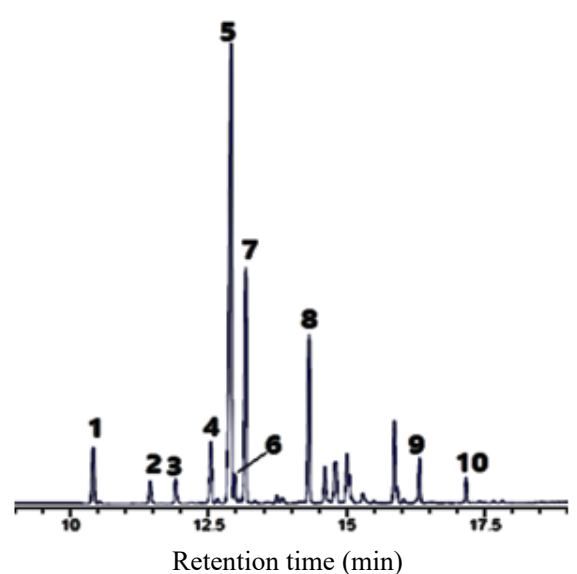

(a)

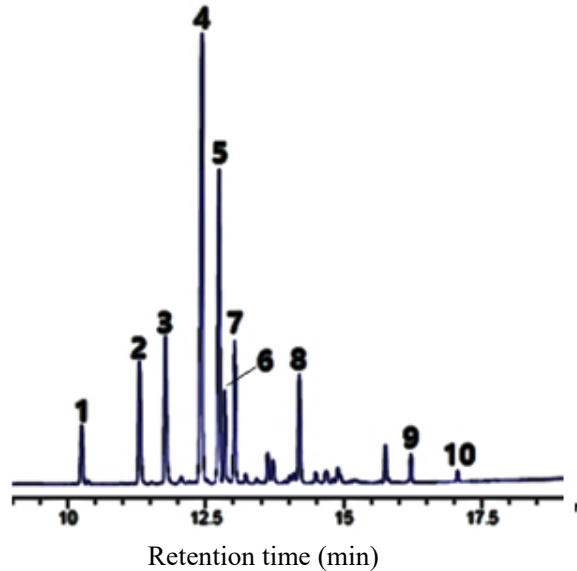

(b)

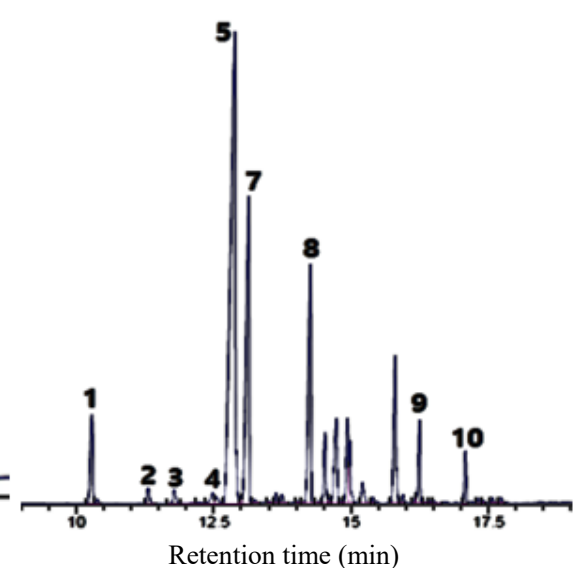

(c)

Figure 2. Gas chromatogram of (a) feed (wash oil), (b) mixed extract phase recovered through by $\mathrm{n}=1 \sim 5\left(\sum_{n=1}^{5} E_{n}\right)$ and (c) raffinate phase $\left(R_{5}\right)$ recovered by $n=5$. Experimental conditions: $y_{w, 0}=0.05, S_{1} / R_{0}=1, T=303 K, t=72 h$. Peak number 1 : naphthalene, 2: quinoline, 3: iso-quinoline, 4: indole, 5: 2-methylnaphthalene, 6: quinaldine, 7: 1-methylnaphthalene, 8: biphenyl, 9: dibenzofuran, 10: fluorene.

\subsection{Batch Equilibrium Extraction}

\subsubsection{Definition Equation}

The distribution coefficient of component $\mathrm{i}$ obtained at the nth stage, $\left(\mathrm{m}_{\mathrm{i}}\right)_{n}$, is defined as:

$$
\left(\mathrm{m}_{\mathrm{i}}\right)_{n}=\left(\mathrm{y}_{\mathrm{i}}\right)_{n} /\left(\mathrm{x}_{\mathrm{i}}\right)_{n}
$$

where $\left(\mathrm{y}_{\mathrm{i}}\right)_{n}$ and $\left(\mathrm{x}_{\mathrm{i}}\right)_{n}$, respectively, denote the mass fraction of component $\mathrm{i}$ in the extract phase and that in the raffinate phase recovered after the nth stage contact run.

The selectivity of component $i$ in reference to 2MNA at the nth stage, $\left(\beta_{i, 2 \mathrm{MNA}}\right)_{n}$, which is defined as the ratio of the distribution coefficient for component $i$ to that for 2MNA, was calculated by Equation (2).

$$
\left(\beta_{\mathrm{i}, 2 \mathrm{MNA}}\right)_{n}=\left(\mathrm{m}_{\mathrm{i}}\right)_{n} /\left(\mathrm{m}_{2 \mathrm{MNA}}\right)_{n}
$$

The residual rate of component $i$ in the raffinate phase recovered from the nth stage $\left(\mathrm{R}_{\mathrm{i}}\right)_{n}$ and residual rate of the raffinate phase $\left(\mathrm{R}_{\mathrm{r}}\right)_{n}$, respectively, are defined as:

$$
\begin{gathered}
\left(\mathrm{R}_{\mathrm{i}}\right)_{n}=\mathrm{R}_{\mathrm{n}} \times\left(\mathrm{x}_{\mathrm{i}}\right)_{n} /\left\{\mathrm{R}_{0} \times\left(\mathrm{x}_{\mathrm{i}}\right)_{0}\right\} \times 100 \% \\
\left(\mathrm{R}_{\mathrm{r}}\right)_{n}=\left(\mathrm{R}_{\mathrm{n}} / \mathrm{R}_{0}\right) \times 100 \%
\end{gathered}
$$

where $R_{0}, R_{n}$ and $\left(x_{i}\right)_{0}$ refer to the mass of a raw material (wash oil), that of the raffinate recovered after the nth stage contact run, and the mass fraction of component $i$ in a raw material (wash oil), respectively.

\subsubsection{Review of Mass Balance and Reproducibility}

As a result of calculating Equation (5) by substituting the measured values from this study to both sides of the mass balance equation, expressed as follows, the values of both sides were almost the same.

$$
\mathrm{R}_{\mathrm{n}-1} \times\left(\mathrm{x}_{\mathrm{i}}\right)_{n-1}-\mathrm{R}_{\mathrm{n}} \times\left(\mathrm{x}_{\mathrm{i}}\right)_{n}=\mathrm{E}_{\mathrm{n}} \times\left(\mathrm{y}_{\mathrm{i}}\right)_{n}-\mathrm{S}_{\mathrm{n}} \times\left(\mathrm{y}_{\mathrm{i}}\right)_{0}
$$

where $S_{n}$ and $\left(y_{i}\right)_{0}$ represent the mass of the fresh solvent put into the nth stage and the mass fraction of component $\mathrm{i}$, respectively. The values of $\left(\mathrm{y}_{\mathrm{i}}\right)_{0}$ for all components in this study are zero, regardless of the number of the equilibrium extraction. From this result, it was estimated that the measured values through the entire experiment in this study were 
very satisfactory. In addition, the experiments were replicated twice or three times under the same conditions to confirm the reproducibility of the measured value. The range of mass variation of component $i$ in the raffinate phase or the extract phase was very good, within $\pm 5 \%$.

\subsubsection{Confirmation of Equilibrium Arrival Time}

To confirm the time of reaching the equilibrium, the raffinate phases and the extract phases recovered through contact (contact time: $12 \mathrm{~h}, 24 \mathrm{~h}, 72 \mathrm{~h}, 96 \mathrm{~h}$ ) with a raw material and a solvent were analyzed. The compositions of the raffinate phase and the extract phase recovered through contact for more than $48 \mathrm{~h}$ were almost the same, regardless of the contact time. Therefore, the liquid-liquid contact time of this study was maintained at $72 \mathrm{~h}$.

\subsubsection{Reduction Performance}

Figure $3 a, b$, respectively, represent the effects of $y_{w, 0}$ on $\left(m_{i}\right)_{1}$ and $\left(\beta_{i, 2 M N A}\right)_{1}$ in the first stage $(n=1)$ under fixed conditions $\left(\mathrm{S}_{1} / \mathrm{R}_{0}=1, \mathrm{~T}=303 \mathrm{~K}, \mathrm{t}=72 \mathrm{~h}\right)$. Increasing $\mathrm{y}_{\mathrm{W}, 0}$ resulted in decreasing $\left(\mathrm{m}_{\mathrm{i}}\right)_{1}$ because the polarity of an extract phase increases with an increase in its moisture. Therefore, $\left(\mathrm{m}_{\mathrm{i}}\right)_{1}$, accordingly, decreased sharply as $\mathrm{y}_{\mathrm{w}, 0}$ increased. The $\left(\mathrm{m}_{\mathrm{i}}\right)_{1}(\mathrm{i}=\mathrm{QU}, \mathrm{IQU}, \mathrm{IN})$ of three kinds of NC were much higher than those of NA, 2MNA and BP. This indicates that the polarities of three kinds of NC are much higher than those of the other components of the three kinds. As shown from the definition equation of $\left(\beta_{\mathrm{i}, 2 \mathrm{MNA}}\right)_{1}$ and the above-mentioned results of $\left(\mathrm{m}_{\mathrm{i}}\right)_{1}$, the $\left(\beta_{\mathrm{i}, 2 \mathrm{MNA}}\right)_{1}$ of three kinds of NC, inversely, increased with an increase in $\mathrm{y}_{\mathrm{w}, 0}$. The values of $\left(\beta_{\mathrm{QU}, 2 \mathrm{MNA}}\right)_{1}$ and $\left(\beta_{\text {IQU,2MNA }}\right)_{1}$ were observed to be almost the same, and it was difficult to separate between those components. The sequence of $\left(\beta_{\mathrm{i}, 2 \mathrm{MNA}}\right)_{1}$ for the entire component of this study was IN $>$ QU $=$ IQU $>N A>B P$. In $\mathrm{y}_{\mathrm{w}, 0}=0.05 \sim 0.3$, the ranges of $\left(\beta_{\mathrm{i}, 2 \mathrm{MNA}}\right)_{1}$ for $\mathrm{QU}$, IQU and IN, which are the components of which this study aims to reduce the concentrations, were 19 57, 19 56, and 50 79, respectively.
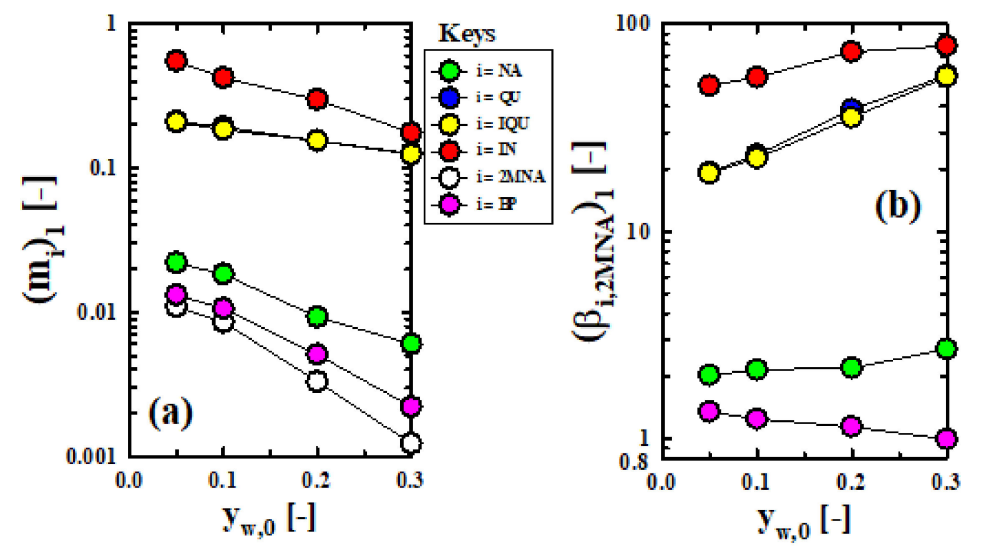

Figure 3. Changes in $(\mathbf{a})\left(\mathrm{m}_{\mathrm{i}}\right)_{1}$ and $(\mathbf{b})\left(\beta_{\mathrm{i}, 2 \mathrm{MNA}}\right)_{1}$ according to $\mathrm{y}_{\mathrm{w}, 0}$. Experimental conditions: $\mathrm{S}_{1} / \mathrm{R}_{0}=1, \mathrm{~T}=303 \mathrm{~K}, \mathrm{t}=72 \mathrm{~h}$.

Figure $4 \mathrm{a}, \mathrm{b}$, respectively, show the changes in $\left(\mathrm{m}_{\mathrm{i}}\right)_{n}$ and $\left(\beta_{\mathrm{i}, 2 \mathrm{MNA}}\right)_{n}$ according to the number of equilibrium extractions obtained through the five-stage extraction performed under $\mathrm{y}_{\mathrm{w}, 0}=0.05$, selected in this study considering the balance of $\left(\mathrm{m}_{\mathrm{i}}\right)_{1}$ and $\left(\beta_{\mathrm{i}, 2 \mathrm{MNA}}\right)_{1}$ for the NCs in Figure 3. Regardless of the number of equilibrium extractions, $\left(\mathrm{m}_{\mathrm{i}}\right)_{n}$ in all of the components in this study showed almost the same value. Therefore, we could not recognize a change in $\left(\mathrm{m}_{\mathrm{i}}\right)_{n}$ according to the number of equilibrium extractions. The sequence of $\left(\mathrm{m}_{\mathrm{i}}\right)_{n}$ was $\mathrm{IN}>\mathrm{QU}=\mathrm{IQU}>\mathrm{NA}>\mathrm{BP}>2 \mathrm{MNA}$. The same as the above-mentioned tendency of $\left(\mathrm{m}_{\mathrm{i}}\right)_{n}$, the $\left(\beta_{\mathrm{i}, 2 \mathrm{MNA}}\right)_{n}$ of three kinds of NC (QU, IQU, IN) was much greater than that of other the three kinds of compounds (NA, BP, 2MNA), and ( $\left.\beta_{\mathrm{QU}, 2 \mathrm{MNA}}\right)_{n}$ and $\left(\beta_{\mathrm{IQU}, 2 \mathrm{MNA}}\right)_{n}$ were almost the same. Through this, we could see that formamide extraction is effective in reducing NCs from the wash oil, but it is difficult to separate QU and IQU. The selectivity 
of QU, IQU and IN were about 21, 20 and 57, respectively, regardless of the number of equilibrium extractions. It was found that the formamide extraction method used in this study showed particularly high selectivity to IN among the NC components. The sequence of selectivity for all of the components of this study was the same as that of the above-mentioned $\left(\mathrm{m}_{\mathrm{i}}\right)_{n}$.
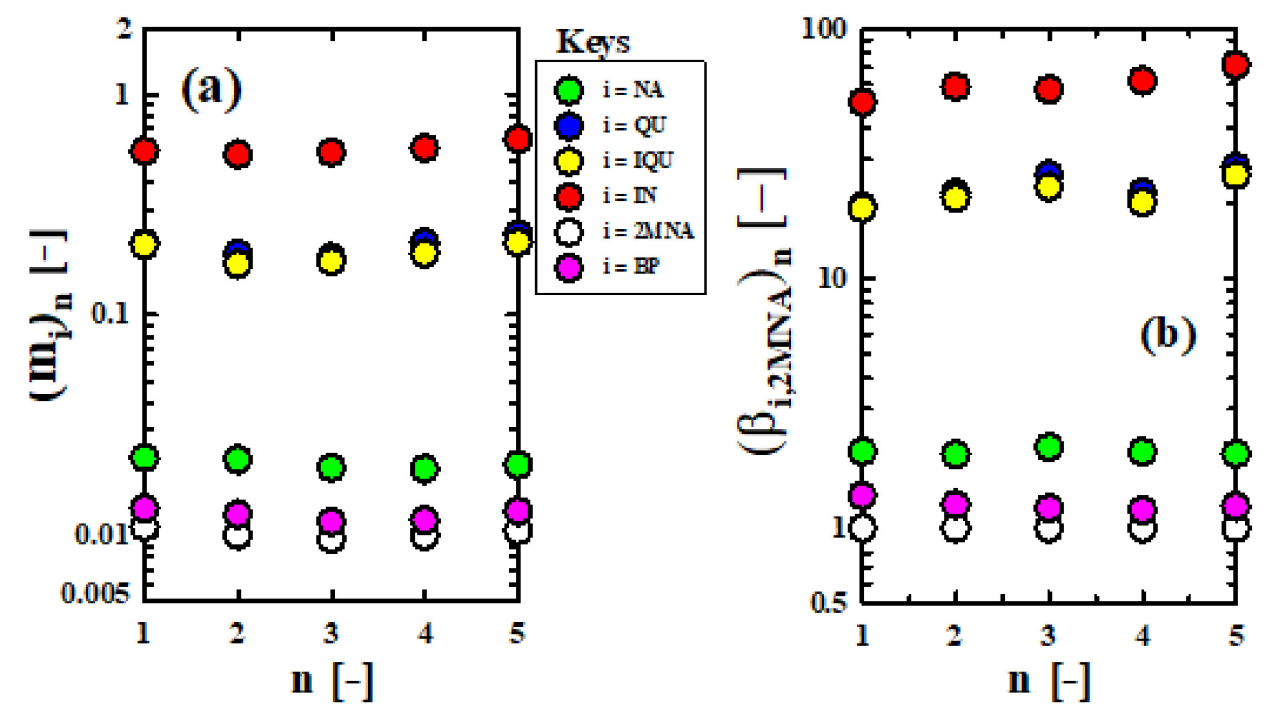

Figure 4. Changes in $(\mathbf{a})\left(\mathrm{m}_{\mathrm{i}}\right)_{\mathrm{n}}$ and $(\mathbf{b})\left(\beta_{\mathrm{i}, 2 \mathrm{MNA}}\right)_{\mathrm{n}}$ according to number of equilibrium extractions $(\mathrm{n})$. Experimental conditions: $\mathrm{y}_{\mathrm{w}, 0}=0.05, \mathrm{~S}_{1} / \mathrm{R}_{0}=1, \mathrm{~T}=30^{\circ} \mathrm{C}, \mathrm{t}=72 \mathrm{~h}$.

Figure $5 \mathrm{a}-\mathrm{c}$ presents the changes in $\left(\mathrm{x}_{\mathrm{i}}\right)_{n},\left(\mathrm{R}_{\mathrm{i}}\right)_{n}$ and $\left(\mathrm{R}_{\mathrm{r}}\right)_{n}$ according to the number of equilibrium extractions, respectively. The $n=0$ shown in these figures refers to the wash oil used as a raw material in this study. As predicted by Figure 3a, three kinds of $\mathrm{NC}$ with large polarity are extracted into the extraction phase, and it can be seen that the $\left(\mathrm{x}_{\mathrm{i}}\right)_{n}$ of three kinds of NC in raffinate phase decrease rapidly as the number of equilibrium extractions increases. Conversely, the other three components, aside from the three kinds of NC, showed a tendency to increase slightly as the number of equilibrium extractions increases. This is because the compositions of the three kinds of NC contained in the wash oil are very low, so even if a large amount of the NC with large polarity is extracted as the equilibrium extractions proceed, the composition change in components such as 2MNA in the raffinate phase is not significantly affected. At $n=5$, the $\left(\mathrm{x}_{\mathrm{i}}\right)_{n}$ of each $\mathrm{NC}$, which are the target components for concentration reduction in this study, was significantly lower than that of each NC contained in the wash oil used as a raw material in this study. Through this, the effect of reducing NC in the wash oil by formamide extraction could be reconfirmed. Conversely, it can be seen from Figure $5 \mathrm{~b}$ that the $\left(\mathrm{R}_{\mathrm{i}}\right)_{n}$ of the three kinds of NC present in the raffinate oil decreases rapidly as the equilibrium extraction progresses, but the $\left(\mathrm{R}_{\mathrm{i}}\right)_{n}$ of the other three kinds of components decreases very slowly. The $\left(\mathrm{R}_{\mathrm{i}}\right)_{n}$ of $\mathrm{QU}, \mathrm{IQU}$ and IN at $n=5$ were about $31 \%, 35 \%$ and $6.6 \%$, respectively. Considering the $\left(\mathrm{R}_{\mathrm{i}}\right)_{n}$ of QU, IQU and IN obtained from a five-stage equilibrium, it is expected that the raffinate oil containing little amounts of NC will be recovered when the extraction operation is performed using a tower-type multistage apparatus under optimal extraction conditions. As the equilibrium extraction proceeds from Figure $5 c$, it can be seen that $\left(R_{\mathrm{r}}\right)_{n}$ decreases, indicating about $86 \%$ in $n=5$. It was found in particular that the formamide extraction method, which has a very high selectivity for NC compared to other components, presented a very high residual rate of the product (raffinate oil) with improved quality. 

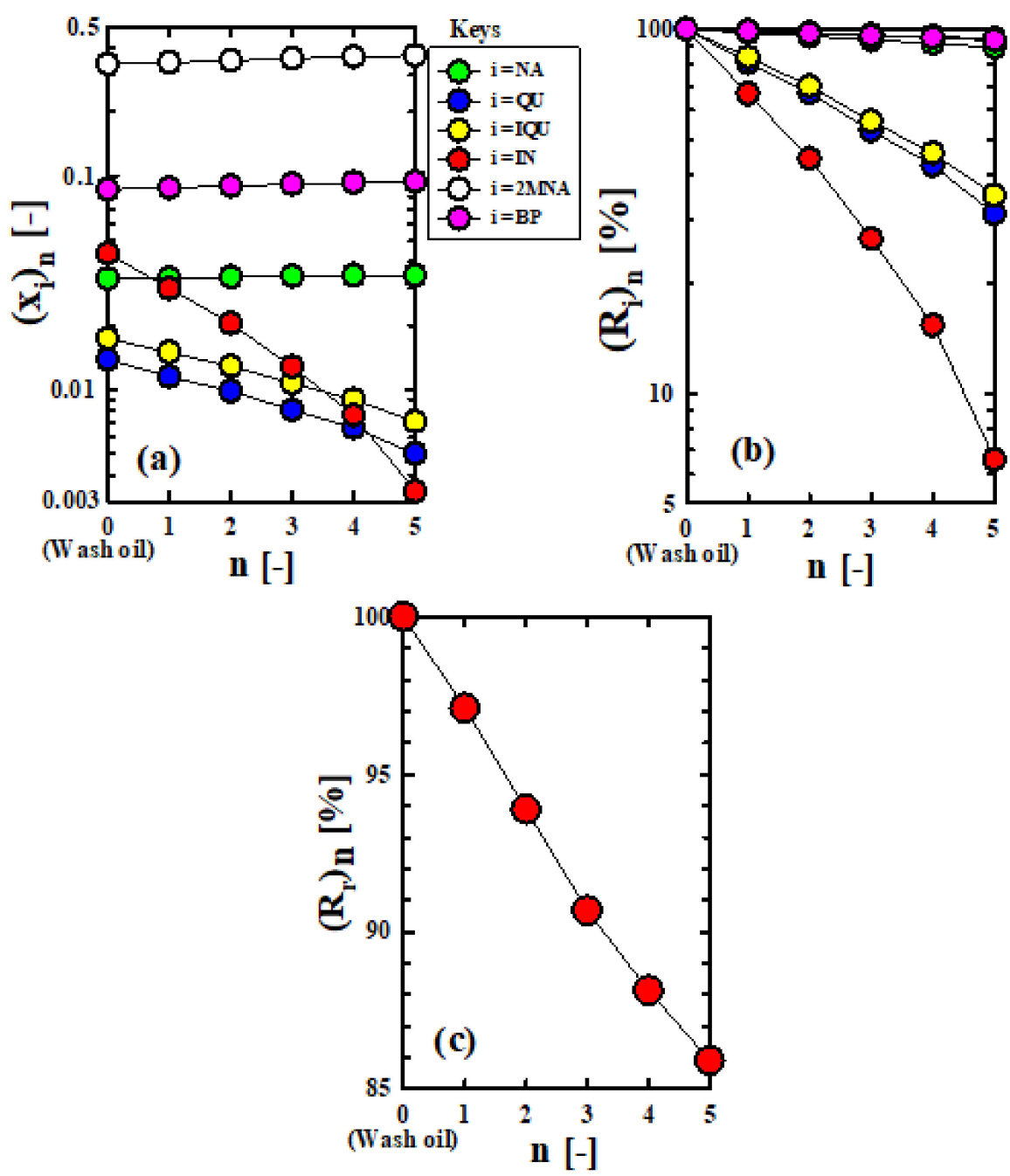

Figure 5. Changes in $(a)\left(x_{i}\right)_{n},(b)\left(R_{i}\right)_{n}$, and (c) $(R)_{n}$ according to number of equilibrium extractions (n). Experimental conditions: $\mathrm{y}_{\mathrm{w}, 0}=0.05, \mathrm{~S}_{1} / \mathrm{R}_{0}=1, \mathrm{~T}=303 \mathrm{~K}, \mathrm{t}=72 \mathrm{~h}$.

\subsubsection{Comparison of Gas Chromatogram}

Figure $2 b, c$, respectively, show the gas chromatograms of a mixed extract phase $\left(\sum_{n=1}^{5} E_{n}\right)$ and the raffinate phase $\left(\mathrm{R}_{5}\right)$ recovered from $n=5$. When the gas chromatogram of the mixed extract phase in Figure 2b was compared with that of the wash oil in Figure 2a, the peak heights of four kinds of NC (peak numbers 2, 3, 4, 6) were considerably increased, but those of the other compounds were considerably decreased. The gas chromatogram of the raffinate phase $\left(R_{5}\right)$ of Figure $2 \mathrm{c}$ was also very different from that of the wash oil. Four kinds of NC were extracted through a five-stage extraction, so that the peak height of each NC decreased, but the peak heights of other compounds were much higher. Through these gas chromatograms, it was possible to reconfirm the effect of formamide extraction on the reduction of NCs present in the wash oil.

When comprehensively considering the results of this study, as described above, the formamide extraction method is expected to be one of the most useful methods in reducing NCs in the wash oil.

\subsubsection{Reduction Process of NC from Wash Oil}

The process for the reduction of NCs from wash oil was investigated using the experimental results obtained from the formamide extraction [2]. The proposed process is composed of one extraction tower, one washing tower and two distillation towers, as shown in Figure 6. Tower 1 is an extraction column to separate NCs from all other compounds in 
the wash oil. Tower 2 is an atmospheric distillation column to remove water contained in the extract phase and tower 3 is a vacuum distillation column to separate formamide and the NC. Additionally, tower 4 is a washing column to remove the formamide present in the raffinate phase.

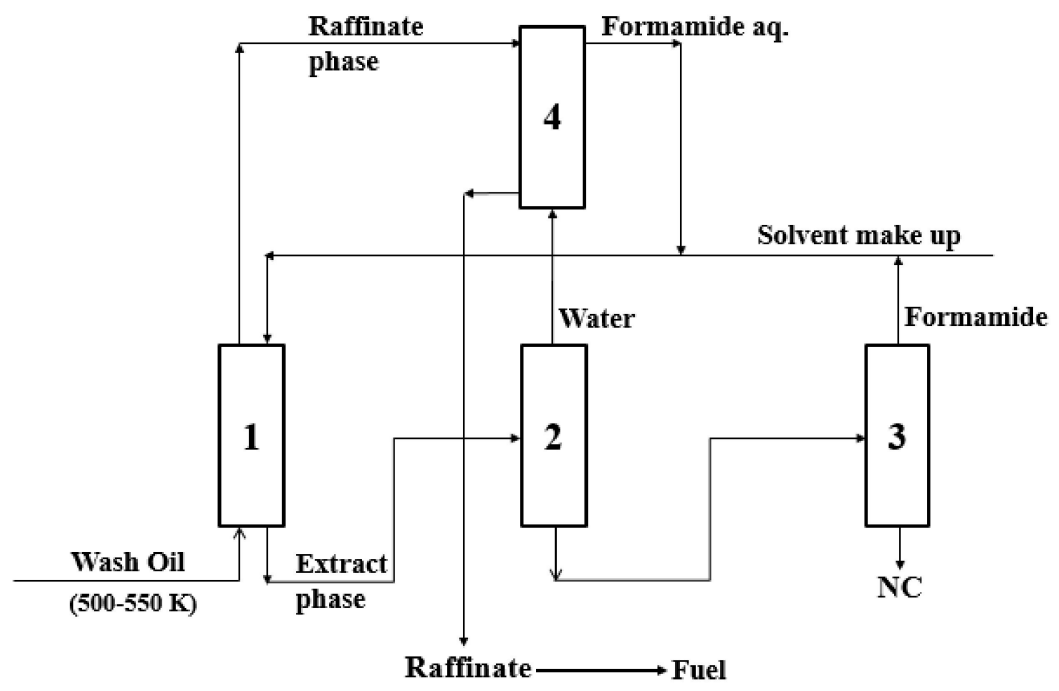

Figure 6. Reduction process of NCs contained in wash oil [2]. Tower no. 1: extraction tower, tower nos. 2, 3: distillation towers, tower no. 4: washing tower.

\section{Conclusions}

Until now, complex reaction extraction methods have been used to reduce NCs from a coal tar fraction, but today, the development of a simpler and more efficient reduction method is needed. From this perspective, this study experimentally performed a reduction of NCs contained in wash oil by applying a batch equilibrium extraction. The formamide extraction method, a quality improvement method of wash oil applied in this study, produced very effective results in reducing the NCs of wash oil, and it is expected to be an alternative to the complex reaction extraction methods that have been applied thus far.

Funding: The research received no external funding.

Institutional Review Board Statement: Not applicable.

Informed Consent Statement: Not applicable.

Data Availability Statement: The data presented in this study are available within the article (tables and figures).

Conflicts of Interest: The author declares no conflict of interest.

\section{References}

1. Kim, S.J. Separation and Purification of Indole in Model Coal Tar Fraction of 9 Compounds System. Polycycl. Aromat. Compd. 2019, 39, 60-72. [CrossRef]

2. Kang, H.-C.; Kim, S.J. Comparison of Methanol with Formamide on Separation of Nitrogen Heterocyclic Compounds from Model Coal Tar Fraction by Batch Cocurrent Multistage Equilibrium Extraction. Polycycl. Aromat. Compd. 2016, 36, 745-757. [CrossRef]

3. Kim, S.J.; Chun, Y.J. Separation of Nitrogen Heterocyclic Compounds from Model Coal Tar Fraction by Solvent Extraction. Sep. Sci. Technol. 2005, 40, 2095-2109. [CrossRef]

4. Egashira, R.; Nagai, M. Separation of Nitrogen Heterocyclic Compounds Contained in Coal Tar Absorption Oil Fraction by Solvent Extraction. J. Jpn. Pet. Inst. 2000, 43, 339-345. [CrossRef]

5. Xu, D.; Zhang, M.; Gao, J.; Zhang, L.; Zhou, S.; Wang, Y. Separation of heterocyclic nitrogen compounds from coal tar fractions via ionic liquids: COSMO-SAC screening and experimental study. Chem. Eng. Commun. 2019, 206, 1199-1217. [CrossRef]

6. Jiao, T.; Zhuang, X.; He, H.; Zhao, L.; Li, C.; Chen, H.; Zhang, S. An ionic liquid extraction process for the separation of indole from wash oil. Green Chem. 2015, 17, 3783-3790. [CrossRef] 
7. Zhang, L.; Xu, D.; Gao, J.; Zhou, S.; Zhao, L.; Zhang, Z. Extraction and mechanism for the separation of neutral N-compounds from coal tar by ionic liquids. Fuel 2017, 194, 27-35. [CrossRef]

8. Sakanishi, K.; Obata, H.; Mochida, I.; Sakaki, T. Capture and Recovery of indole from methylnaphthalene oil in a continuous supercritical $\mathrm{CO}_{2}$ extraction apparatus over a fixed bed of anion-exchange resin. Ind. Eng. Chem. Res. 1996, 35, 335-337. [CrossRef]

9. Sakanishi, K.; Obata, H.; Mochida, I.; Sakaki, T. Removal and Recovery of quinoline bases from methylnaphthalene oil in a semicontinuous supercritical $\mathrm{CO}_{2}$ separation apparatus with a fixed bed of supported aluminum sulfate. Ind. Eng. Chem. Res. 1995, 34, 4118-4121. [CrossRef]

10. Uemasu, I. Effect of methanol-water mixture solvent on concentration of indole in coal tar using $\beta$-cyclodextrin as complexing agent. J. Jpn. Pet. Inst. 1991, 34, 371-374. [CrossRef]

11. Ukegawa, K.; Matsumura, A.; Kodera, Y.; Kondo, T.; Nakayama, T.; Tanabe, H.; Yoshida, S.; Mito, Y. Solvent extraction of nitrogen compounds from a coal tar fraction. (Part 1). Effect of extraction conditions on the extraction rate and the selectivities of nitrogen compounds. J. Jpn. Pet. Inst. 1990, 33, 250-254. [CrossRef]

12. Egashira, R.; Salim, C. Solvent Extraction of nitrogen heterocyclic compounds contained in coal tar absorption oil fraction. improvement of separation performance by addition of aluminum chloride to solvent. J. Jpn. Pet. Inst. 2001, 44, 178-182. [CrossRef]

13. Kodera, Y.; Ukegawa, K.; Mito, Y.; Komoto, M.; Ishikawa, E.; Nakayama, T. Solvent extraction of nitrogen compounds from coal liquids. Fuel 1991, 70, 765-769. [CrossRef] 